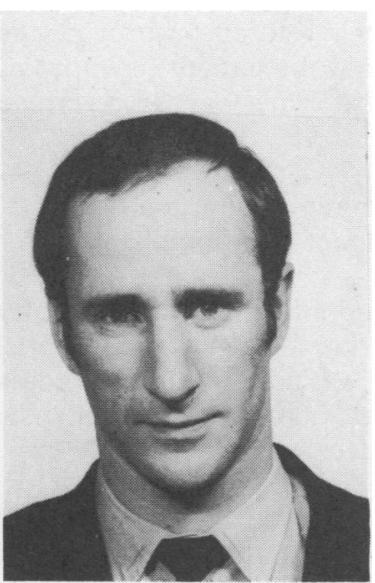

C. Abbott

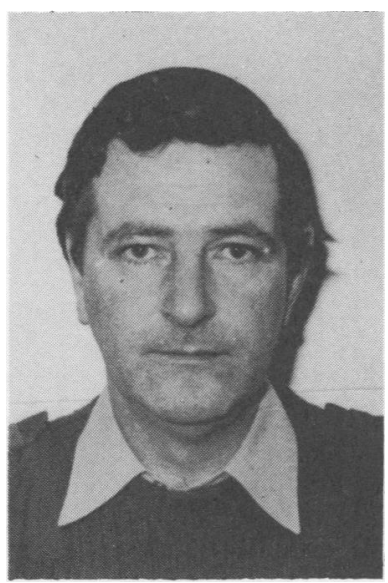

Bouchier-Hayes

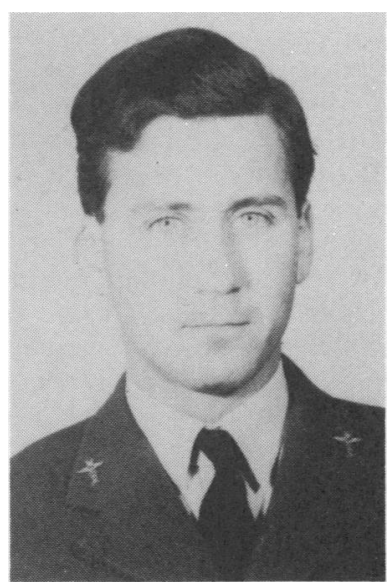

H. Hunt

\title{
A COMPARISON OF THE EFFICACY OF NAPROXEN SODIUM AND A PARACETAMOL/DEXTROPROPOXYPHENE COMBINATION IN THE TREATMENT OF SOFT.TISSUE DISORDERS
}

\author{
C. J. A. ABBOTT, MRCGP* , T. A. I. BOUCHIER-HAYES, MRCGP** and H. A. HUNT, FRCGP† \\ *Medical Centre, R.A.F. Brize Norton, Oxon (Present address: R.A.F. Brawdy, W. Wales) \\ ** Medical Centre, Chelsea Barracks, London \\ (Present Address - Royal Military Academy, Sandhurst, CAMBERLEY, Surrey) \\ tMedical Centre, R.A.F. Lyneham, Wilts.
}

\begin{abstract}
Ninety-eight patients were admitted to a single-blind parallel study comparing the efficacy of naproxen sodium with a paracetamol/dextropropoxyphene combination in the treatment of soft-tissue disorders. The two study groups were well matched in all respects.

After seven days of treatment patients in the naproxen sodium group had less residual symptoms and more of them were considered cured. These patients also had a significantly lower mean-pain-score, tended to have less daily symptoms and recorded a significantly greater initial improvement in their condition.

Fewer side-effects were recorded by the naproxen sodium-treated patients. One patient from each group withdrew from the study because of side-effects.

It was concluded that in the treatment of non-articular soft-tissue disorders the use of a rapidly-acting non-steroidal anti-inflammatory drug, naproxen sodium, gave a better clinical response than did treatment with a simple analgesic combination.

\section{INTRODUCTION}

The traditional treatment for soft-tissue injuries consists of rest, elevation, support and immobilisation. Simple analgesics are usually prescribed to alleviate any pain or discomfort which may accompany the injuries.

It is now thought that at least part of the inflam-

matory picture observed in these conditions is due either to the direct effects of prostaglandins liberated locally as a result of tissue damage, or to their potentiation of more classical chemical mediators. Consequently, in treating these injuries, the use of an analgesic drug which is also capable of inhibiting prostaglandin production could aid recovery.
\end{abstract}


Naproxen is a non-steroidal anti-inflammatory drug which has been shown to inhibit prostaglandin synthesis (Ferriera et al, 1975) and which has potent analgesic, anti-pyretic and anti-inflammatory properties (Roszkowski et al, 1971). When administered as the sodium salt, naproxen is quickly absorbed from the gastro-intestinal tract, and in pain-relief studies it produces a rapid clinical effect (Filtzer, 1980; Sevelius et al, 1980a; Sevelius et al, 1980b). These are properties which should be advantageous in the treatment of acute painful states such as occur in the non-articular musculoskeletal and soft-tissue disorders.

This study compares the efficacy of naproxen sodium with that of a paracetamol/dextropropoxyphene mixture, a simple analgesic preparation which is widely prescribed in the treatment of these injuries.

\section{METHODS}

Patients were drawn from three separate groups of Armed Forces personnel who were under the care of the individual medical staff conducting the study. Patients admitted to the study were those who had recently suffered traumatic or sports-induced soft-tissue injuries.

The clinical assessment of the patient at the admission visit was carried out as follows. The overall severity of the injury was classified as being mild, moderate or severe. The physician then conducted a clinical examination which allowed him to grade the severity of the patient's symptoms. The presence of pain on passive movement, tenderness to firm palpation, swelling and limitation of movement were classified on a simple four-point scale as none, mild, moderate or severe.

Patients were allocated randomly to treatment with either naproxen sodium $275 \mathrm{mg}$ capsules* (1 capsule t.d.s.) or to a preparation containing paracetamol $325 \mathrm{mg}$ and dextropropoxyphene hydrochloride $32.5 \mathrm{mg}^{* *}(2$ tablets t.d.s.). The study was run on a single-blind basis and the comparative drugs were provided in identical individual-dose envelopes, packed in identical boxes each of which contained seven days' supply of treatment.

Patients were also provided with a card on which they could keep a daily record of their degree of pain and their ability to move the injured part (on graded fourpoint scales) and the general state of the injury compared with the previous day (much worse $(-2)$, worse $(-1)$, the same $(0)$, better $(+1)$, much better $(+2))$.

A follow-up clinical assessment was carried out after seven days of treatment. On this occasion the state of

"SYNFLEX capsules ®Syntex Pharmaceuticals Ltd.

* "DISTAL GESIC tablets $B$ Dista Products $L$ td. the injury was classified as being cured, improved, the same or worse. An assessment of the patient's symptoms was carried out in exactly the same way as described for the admission visit.

Any unwanted effects suffered during the period of treatment were elicited by indirect questioning.

If the injury were considered to be insufficiently improved at the follow-up visit, then an additional seven-day period of treatment was administered. In these cases a further follow-up assessment was undertaken at the end of the treatment (14 days).

Analysis of results was undertaken using either the Wilcoxon Signed Ranks test or the Mann-Whitney $U$ test.

\section{RESULTS}

The two groups of patients were well matched for age, sex, the type of injury suffered, the sites of injury and the duration of symptoms prior to admission (see Tables I, II and III). Forty-nine patients were admitted to each study group.

\section{TABLE I}

\section{ADMISSION DETAILS OF PATIENTS}

\begin{tabular}{|c|c|c|c|}
\hline $\begin{array}{l}\text { MEAN } \\
\text { AGE (YEARS) }\end{array}$ & & $\begin{array}{l}\text { NAPROXEN } \\
\text { SODIUM } \\
27 \pm 9 \text { (S.D.) }\end{array}$ & $\begin{array}{l}\text { GROUP } \\
\text { PARACETAMOL } \\
\text { DEXTROPRO- } \\
\text { POXYPHENE } \\
25 \pm 7 \text { (S.D.) }\end{array}$ \\
\hline \multirow[t]{2}{*}{ SEX } & MALE & 45 & 46 \\
\hline & FEMALE & 4 & 3 \\
\hline DURATION OF & 0 & 8 & 5 \\
\hline INJURY ON & 1 & 24 & 23 \\
\hline ADMISSION & $2-7$ & 11 & 17 \\
\hline (DAYS) & $>7$ & 6 & 4 \\
\hline
\end{tabular}

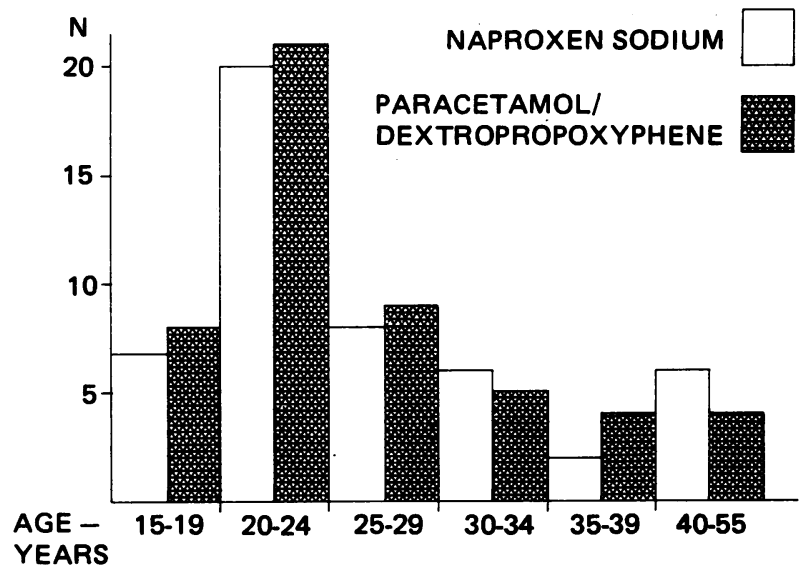

Figure 1. Distribution of patients' ages 
TABLE II

DIAGNOSTIC CATEGORIES OF INU URIES SUFFERED

NAPROXEN SODIUM GROUP

Muscle pulls/tears

Tendonitis/tenosynovitis

Ligamentous and capsular sprains

Low-back/lumbo-sacral injuries

Contusions and bruising

Nerve/intervertebral disc problems

Capsulitis of shoulder

Internal derangement of knee

Joint effusion

PARACETAMOL/ DEXTROPROPOXYPHENE GROUP

$\begin{array}{rr}6 & 4 \\ 4 & 4 \\ 16 & 19 \\ 6 & 5 \\ 7 & 5 \\ 5 & 9 \\ 0 & 3 \\ 4 & 4 \\ 1 & 0\end{array}$

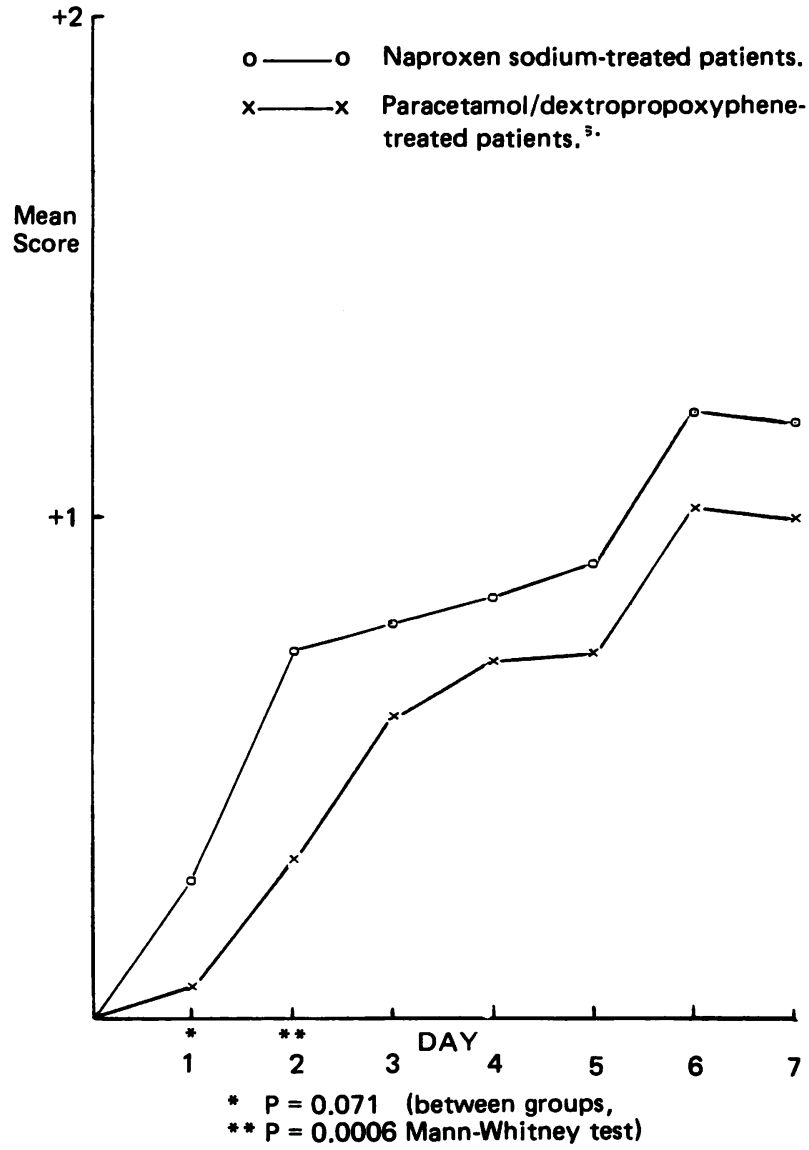

Figure 2:

Patient daily record of change since previous day
As can be seen, most of the patients were male and the majority of the patients $(76 \%)$ admitted to the study were seen within 48 hours of sustaining their injury. Thirteen per cent were seen on the day of injury and $61 \%$ within 24 hours of its occurrence.

On admission both groups contained a high propor tion of patients who had severe or moderate symptoms of pain, tenderness and limitation of movement. The presence of swelling was not so evident.

These observations are reflected in the mean admission symptom-scores which were, except for swelling, relatively high in both treatment groups (Table IV). All the mean admission symptom-scores were similar in the two groups and there were no significant differences between the groups.

By the seven-day assessment the symptom-scores in both treatment groups had decreased significantly from their starting values (Table IV). For all symptoms other than swelling the mean score was lower in the naproxen sodium-treated patients. In the case of tenderness and limitation of movement, the differences between the two treatment groups did not reach statistical significance, but the seven-day mean pain-score is significantly lower in the patients treated with naproxen sodium than in those treated with paracetamol and dextropropoxyphene.

By day three, ten naproxen sodium patients were pain-free, by day five, 20 patients in this group were pain-free and by day seven, 45 patients were pain-free. Comparative figures for those in the other group were seven patients at day three, 15 patients at day five and 41 patients at day seven.

Clinically it was thought that at the seven-day follow- 
up 30 patients in the naproxen sodium group and 23 patients in the combined analgesic group were cured. A further 14 patients treated with naproxen sodium were thought to have improved clinically and the condition of one patient remained unchanged.

In the paracetamol/dextropropoxyphene group 15 patients were thought to be improved and six patients were unchanged or worse.

The analysis of the daily records of the patients' pain and limitation of movement gave mean daily scores which were consistently lower in the naproxen sodium group. None of these differences was statistically significant. However, the comparison of the day-to-day improvement of the injuries recorded by the patients showed that the mean score for the naproxen sodiumtreated group was significantly higher on days one and two of treatment than the corresponding score in the analgesic combination group (Figure 1).

Seven of those patients treated with naproxen sodium reported a total of ten side-effects, while ten of the patients treated with the analgesic combination had 13 side-effects (Table V). Two patients, one from each group, withdrew from the study because of the severity

TABLE III

\section{MAIN BODY REGIONS INVOLVED}

\begin{tabular}{lcc}
\multicolumn{1}{c}{ REGION } & $\begin{array}{c}\text { NAPROXEN SODIUM } \\
\text { GROUP }\end{array}$ & $\begin{array}{c}\text { PARACETAMOL/ } \\
\text { DEXTROPROPOXYPHENE } \\
\text { GROUP }\end{array}$ \\
Arm/Shoulder/neck & 4 & 11 \\
Hand/wrist & 3 & 4 \\
Back & 9 & 7 \\
Chest & 2 & 2 \\
Thigh/calf & 6 & 4 \\
Knee & 6 & 3 \\
Ankle/foot & 19 & 18
\end{tabular}

TABLE IV

MEAN SYMPTOM-SCORES DETERMINED AT ADMISSION AND AFTER 7 DAYS OF DRUG TREATMENT ( \pm S.D.)

SYMPTOM

Pain

Tenderness

Swelling

Limitation

ADMISSION

ASSESSMENT

NAPROXEN SODIUM
$1.74 \pm 0.53$
$1.63 \pm 0.78$
$0.73 \pm 0.84$
$1.76 \pm 0.56$

\begin{abstract}
PARACETAMOL/ DEXTROPROPOXYPHENE
\end{abstract}
$1.76 \pm 0.63$
$1.85 \pm 0.82$
$0.78 \pm 0.92$
$1.71 \pm 0.61$

DAY SEVEN

ASSESSMENT

* Significantly lower than admission values $p<0.001$ (Wilcoxon Signed Ranks test)

$\dagger$ Group means differ significantly $p=0.035$ (Mann-Whitney test)

TABLE V

SIDE-EFFECTS REPORTED DURING THE STUDY

\section{SIDE-EFFECT}

Related to gastro-intestinal tract

Related to central nervous system

Other

TOTAL SIDE-EFFECTS

Number of patients involved
NAPROXEN SODIUM

$\begin{array}{rr}5 & 2 \\ 5 & 9 \\ 0 & 2 \\ 10 & 13 \\ 7 & 10\end{array}$


of their side-effects. The naproxen sodium-treated patient suffered from headache and visual upset and the patient treated with paracetamol and dextropropoxyphene complained of gastric upset and vomiting.

As only seven patients needed treatment for the maximum period, analysis and comparison of the 14 day values were not carried out.

\section{DISCUSSION}

The largest single group of injuries reported in this study consisted of injuries to ligaments and joint capsules with the lower limb being the body region most frequently involved. The types of injury seen and their sites were very similar in the two treatment groups. The similarities also extend to the analysis of age, severity of symptoms and duration of the injury prior to admission to the study. This situation exists despite the fact that patients were drawn from more than one centre and that the soft-tissue classification is a wide one.

The close matching was probably due to the groups of service personnel having a similar social composition and similar types and degrees of activity.

The clinical findings indicate that for all symptoms those patients treated with naproxen sodium fared better than those treated with the simple analgesic combination. The only symptom not fitting this pattern was swelling which was of a low mean score in the two groups of patients even at the initial assessment. The tendency was for the naproxen sodium-treated patients to have less daily pain, to be pain-free earlier, to be more likely to be cured or improved at the end of the treatment and to have less limitation of movement. Patients in this group were found to have a significantly lower mean pain-score at the follow-up visit and they also recorded a significantly greater initial improvement in their condition.
Van Marion (1973) in his study of indomethacin in soft-tissue injuries also noted that a difference between two treatments could be found early during the period of treatment.

In a recent article, Muckle (1980) suggests that analgesic/anti-inflammatory drugs should be given as soon as possible after sustaining the injury if they are to provide maximum benefit. This is best achieved where small sporting groups are closely supervised medically, but is less likely to happen in General Practice where appreciable delays in presentation of the patient can occur. In this study a high percentage of the patients were seen within the optimum time of 24 hours after the injury, a rapidity which reflects the organisation of the Forces general practitioner services. rices.

This study shows that in two similar patient groups suffering from a wide variety of soft-tissue disorders, a group treated with naproxen sodium, an analgesic anti-inflammatory drug, had a better clinical response than one treated with a simple analgesic combination. This supports the findings of a number of studies, particularly in sports injuries, which show that analgesic anti-inflammatory drugs such as ibuprofen (Blonstein, 1974; Muckle, 1974), indomethacin (Buelvas, 1967; Leclerc and Autissier, 1969) and benorylate (Krishnan, 1977), are an effective treatment.

Therefore, naproxen sodium appears to have a useful role to play in the early treatment of non-articular, softtissue injuries.

As resolution of the injury can be seen to start within a few days of such treatment, the rapid initial attainment of therapeutic levels afforded by naproxen sodium would appear to be a useful feature. It enables maximum benefit to be obtained quickly, thereby reducing as much as possible the period of disability suffered by the patient.

\section{REFERENCES}

Blonstein, J. L., 1974 "Brufen in the treatment of boxing injuries." Abstracts of papers on ibuprofen and flurbiprofen. XIII International Congress of Rheumatology, Kyoto, Japan. Curr.Med.Res.Opin.: 50-2.

Buelvas, P. R., 1967 "Action of indomethacin in acute traumatic musculo-skeletal disorders." International Congress Series 143: Abstracts of the Fourth Panamerican Congress of Rheumatology. Amsterdam: Excerpta Medica Found ation: 1.99-1.100.

Ferriera, S. H., Flower, R., Moncada, S., Vane, J. R., 1975 “Inhibition of prostaglandin biosynthesis as mechanism of action of non-steroidal anti-inflammatory drugs." Katona, G., Blengio, J. R., Eds. Inflammation and anti-inflammatory therapy. Proceedings of the International Symposium on Inflammation and Anti-Inflammatory Drugs, Mexico City, February 1974. New York: Spectrum Publication: 135-150.

Filtzer, H. S., 1980 "A double-blind randomized comparison of naproxen sodium, acetaminophen and pentazocine in post-operative pain." Curr.Ther.Res. 27: 283-301. 
Krishnan, G., 1977 "A placebo-controlled double-blind trial of benorylate tablets in the treatment of bursitis and synovitis due to sports injury". Rheumatol. Rehabil. 16: 186-189.

Leclerc, F. P. and Autissier, D., 1969 "Utilisation de l'indométacine dans le traîtment des traumatismes des membres et de leurs séquelles". Gaz.Hôp. (Paris) 1: 31-33.

Muckle, D. S., 1974 "Comparative study of ibuprofen and aspirin in soft-tissue injuries." Rheumatol.Rehabil. 13: 141-147.

Muckle, D. S., 1980 "Advantages of anti-inflammatory agents." Medisport 2: 54-57.

Roszkowski,. A. P., Rooks, W. H., Tomolonis, A. J. and Miller, L. M., 1971 "Anti-inflammatory and analgesic properties of d-2-(6'-methoxy-2'-naphthyl)-propionic acid (Naproxen)." J.Pharmac.Exp.Ther. 179: 114-123.

Sevelius, H., Runkel, R., Segre, E. and Bloomfield, S. S., 1980a “Bioavailability of naproxen sodium and its relationship to clinical analgesic effects". Br.J.Clin.Pharmacol. 10: 259-263.

Sevelius, H., Segre, E. and Bursick, K. 1980b "Comparative analgesic effects of naproxen sodium, aspirin and placebo". J.Clin.Pharmacol. 20: 480-485.

Van Marion, W. F., 1973 "Indomethacin in the treatment of soft-tissue lesions. A double-blind trial against placebo." J.Int.Med.Res. 1: 151-158.

\section{BOOK REVIEW}

Title: MUSCLE AND TENDON INJURIES IN ATHLETES

Authors: V. Krejci and P. Koch, 1976

Trans/ator:

D. Le Vay, 1979

Publisher:

Year Book, Medical Publishers, London and George Thieme, Stuttgart

Price: $£ 5.25 \quad 96$ pages $\quad 85$ figures $\quad$ Flexible plastic cover.

This little book is written primarily for sports physicians, but also had in mind the physiotherapist and the scientifically trained coach and physical educationist. It starts with a description of the various types of muscle injury; the "pulled" muscle - a reversible minor injury, the partial tear, and the complete tear, with theories on the cause of muscle injuries discussed in some detail, including experimental work. The role of infection, among other causes, is highlighted. Apart from high technology electro-diagnostic techniques, simple tests for injury and recovery are described that need no or only simple apparatus applicable to the Casualty Department, the Fracture Clinic, the G.P.'s surgery and the Physiotherapy Room. Remedial exercises for each muscle group are described, and details illustrated for strapping techniques.

Other muscle conditions such as the gelatinous nodules found along the length of muscle fibres are also described, and the differential diagnosis discussed; their treatment with injection of hydrocortisone, electrotherapy, etc. are described, but massage seems the most effective therapy. The authors also support the use of pre-competition massage in prevention of injury, which may be doubted by many, but also the caveats regarding massage in injury treatment.

In a similar way injuries to tendons, their sheaths and paratendinous structures are also discussed, with treatment by cortisone and heparin injection into sheaths, and $x$-ray therapy in stubborn cases, with surgical decompression where indicated. Myositis ossificans is also described briefly - perhaps too briefly. The last third of the book is devoted to the fundamental principles of muscle training and the details of warm-up are well illustrated by photographs. The last chapter discusses rehabilitation. Most of the 98 references are to literature published in German, as would be expected, but 17 are a useful selection in English.

Generally, this book describes muscle and tendon injuries in various sites, and gives details of the treatment of each, much of which can be carried out in general medical or physiotherapy practice, but the indications for specialist hospital treatment are given.

H. E. Robson 